\title{
Decisional capacity to consent to treatment and research in patients affected by Mild Cognitive Impairment. A systematic review and meta-analysis
}

\author{
Giovanna Parmigiani, ${ }^{1, *}$ (1) Antonio Del Casale, ${ }^{2}$ Gabriele Mandarelli, ${ }^{3}$ \\ Benedetta Barchielli, ${ }^{2}$ Georgios D. Kotzalidis, ${ }^{1}$ Fabrizia D'Antonio, ${ }^{2}$ (1) \\ Antonella Di Vita, ${ }^{2,4}$ Carlo de Lena, ${ }^{2}$ and Stefano Ferracuti ${ }^{2}$ \\ ${ }^{1}$ Department of Neuroscience, Mental Health, and Sensory Organs, "Sapienza" University of Rome, Rome, Italy \\ ${ }^{2}$ Department of Human Neurosciences, "Sapienza" University of Rome, Rome, Italy \\ ${ }^{3}$ Interdisciplinary Department of Medicine, Section of Criminology and Forensic Psychiatry, University of Bari "Aldo Moro", Bari, Italy \\ ${ }^{4}$ Department of Psychology, "Sapienza” University of Rome, Rome, Italy
}

Objectives: To perform a meta-analysis of clinical studies on the differences in treatment or research decisionmaking capacity among patients with Mild Cognitive Impairment (MCI), Alzheimer's disease (AD), and healthy comparisons (HCs).

Design: A systematic search was conducted on Medline/Pubmed, CINAHL, PsycINFO, Web of Science, and Scopus. Standardized mean differences and random-effects model were used in all cases.

Setting: The United States, France, Japan, and China.

Participants: Four hundred and ten patients with MCI, 149 with AD, and 368 HCs were included.

Measurements: The studies we included in the analysis assessed decisional capacity to consent by the MacArthur Competence Assessment Tool for Treatment (MAcCAT-T), MacArthur Competence Assessment Tool for Clinical Research (MacCAT-CR), Capacity to Consent to Treatment Instrument (CCTI), and University of California Brief Assessment of Capacity to Consent (UBACC).

Results: We identified 109 potentially eligible studies from 1672 records, and 7 papers were included in the metaanalysis. The meta-analysis showed that there was significant impairment in a decision-making capacity in MCI patients compared to the HCs group in terms of Understanding (SMD $=-1.04,95 \%$ CI: -1.31 to -0.77 , $P<0.001 ; I^{2}=52 \%, P=0.07$ ), Appreciation (SMD $=-0.51,95 \% \mathrm{CI}:-0.66$ to $-0.36, P<0.001 ; I^{2}=0 \%$, $P=0.97$ ), and Reasoning (SMD $=-0.62,95 \% \mathrm{CI}:-0.77,-0.47, P<0.001 ; I^{2}=0 \%, P=0.46$ ). MCI patients scored significantly higher in Understanding $\left(\mathrm{SMD}=1.50,95 \% \mathrm{CI}: 0.91,2.09, P=0.01, I^{2}=78 \%, P=0.00001\right)$ compared to patients affected by $\mathrm{AD}$.

Conclusions: Patients affected by MCI are at higher risk of impaired capacity to consent to treatment and research compared to $\mathrm{HCs}$, despite being at lower risk compared to patients affected by AD. Clinicians and researchers need to carefully evaluate decisional capacity in MCI patients providing informed consent.

Key words: capacity assessment, mental capacity, Mild Cognitive Impairment (MCI), Alzheimer's disease (AD)

\section{Introduction}

Mild Cognitive Impairment (MCI) is a syndrome characterized by a decline in cognitive functions

Correspondence should be addressed to: Giovanna Parmigiani, Department of Neuroscience, Mental Health, and Sensory Organs, University of Rome "Sapienza", via di Grottarossa 1035-1039, 00189, Rome, Italy. Phone + 39 3394575795; Fax + 39 633776682. Email: giovanna.parmigiani@uniroma1.it. Received 03 Aug 2020; revision requested 03 Aug 2020; revised version received 11 Nov 2020; accepted 27 Nov 2020. First published online 15 Feb 2021. greater than expected for age and education, but that does not interfere notably with daily life activities (Gauthier et al., 2006). Prevalence in the elderly general population ( $>65$ years) ranges from $3 \%$ to $19 \%$, and more than half of the affected patients develop dementia within 5 years (Gauthier et al., 2006). Patients with MCI can be considered as a risk state for dementia and represents a strategic intervention point (Burns and Zaudig, 2002; 
Petersen and Morris, 2005). As a consequence, patients affected by MCI are increasingly involved in clinical trials aimed at testing new anti-dementia treatments and interventions and often receive dementia-related medication (Ilhan Algin et al., 2017; Ma et al., 2017; Petersen et al., 2005).

Several studies reported impaired decisional capacity to consent to treatment or research in this group of patients (Appelbaum, 2010; Griffith et al., 2010; Han et al., 2015; Jefferson et al., 2008; 2012; Lui et al., 2012; Mittal et al., 2007; Okonkwo et al., 2007; 2008a; 2008b; Simpson, 2010). Hence, patients with MCI are a clinical population at risk of decisional incapacity, whose treatment requires clinicians to carefully find the proper balance between respecting the right of capable patients to make choices (even if clinicians do not approve) about their treatment or participation in clinical trials and the right of incapable patients to be protected from the possible harmful consequences of their improper decisions.

Meeting three criteria is required to ensure an adequate informed consent acquisition, namely, full information disclosure, voluntariness, and patient's capacity to make a decision (Appelbaum, 2007). Following the model of Grisso and Appelbaum decisional capacity consists of four elements, i.e. understanding, appreciating, reasoning, and expressing a choice (Appelbaum, 2007). The capacity threshold to consent to clinical research has different characteristics from that for treatment, including understanding and manipulating information related to the possibility to receive a placebo or not benefitting directly from the experimental intervention, as well as the possibility to withdraw from the study at any time without negative consequences, or the risk for serious or unknown adverse events (Dunn and Jeste, 2001; Parmigiani et al., 2016). Patients involved in clinical research moreover might fail to acknowledge the distinction between research and usual care, and assume that decisions about their care will be made only for their individual benefit, a process defined as therapeutic misconception (Dunn et al., 2006b). In addition, requirements for decisional capacity can vary by jurisdiction and according to different research protocols or medical treatments (the higher the risk, the higher is the required decisional capacity level).

When performing decisional capacity evaluations, physicians tend to rely on their clinical judgment; however the reliability of clinician-based capacity evaluation criteria has been questioned, especially when unstructured evaluations are performed (Raymont et al., 2004). Such an issue is of particular concern especially when assessing patients whose cognitive functioning is half-way between being completely intact and grossly compromised (Appelbaum, 2010), such as for patients affected by MCI.
To overcome this issue, several tools have been developed, which are aimed at guiding and supporting the clinician when assessing decisional capacity to consent to treatment or research (Appelbaum and Grisso, 2001; Dunn et al., 2006a; Grisso et al., 1997; Janofsky et al., 1992; Jeste et al., 2007; Marson et al., 1995; Parmigiani et al., 2016), among which the most widely used are the MacArthur Competence Assessment Tool for Treatment (MAcCAT-T) (Grisso and Appelbaum, 1998) and the MacArthur Competence Assessment Tool for Clinical Research (MacCAT-CR) (Appelbaum and Grisso, 2001).

Decisional capacity to consent to medical treatment (Appelbaum, 2007; Hamann et al., 2011; Lui et al., 2012; Martin et al., 2008; Moye et al., 2006; Okonkwo et al., 2007; 2008a; 2008b; Palmer et al., 2004; Raymont et al., 2004) and to clinical research (Jefferson et al., 2008; 2012; Mittal et al., 2007) are negatively associated with an executive (Koren et al., 2005; Mandarelli et al., 2012) and global cognitive dysfunctions (Karlawish et al., 2002; Mandarelli et al., 2014; 2018; 2019; Palmer et al., 2005; Palmer and Savla, 2007; Stroup et al., 2005).

Previous reviews have investigated the prevalence of mental incapacity to consent in patients affected by cognitive impairment and Alzheimer's disease (AD) (Appelbaum, 2010; Kim et al., 2002; Simpson, 2010; van Duinkerken et al., 2018), but the clinical, demographical, and neuropsychological factors associated with the decisional capacity in patients with MCI remains elusive. We deem that identifying these factors would inform strategies to develop interventions tailored at enhancing decisional capacity in this vulnerable group of patients. The objective of this systematic review and meta-analysis was to identify which clinical, demographic, and treatment-related variables were associated with informed consent to treatment and research in patients with MCI, and to investigate the differences in the decisional capacity to consent to treatment and research between patients with MCI, $\mathrm{AD}$, and healthy comparisons (HCs).

\section{Materials and methods}

This systematic review was conducted in accordance with the Preferred Reporting Items for Systematic Review and Meta-Analyses (PRISMA) guidelines (Liberati et al., 2009).

\section{Literature search}

We used a systematic search strategy to identify relevant papers. We conducted a two-step literature search on 19 October 2019. As a first step, the Medline/ Pubmed, CINAHL, PsycINFO, Web of Science, and Scopus databases were searched, with the following string: ("Mild Cognitive Impairment" OR "mild 
neurocognitive disorder") AND (“decision making" OR "informed consent” OR "decisional capacity" OR "mental competency" OR "mental capacity"). The second step involved the implementation of an additional electronic search based on a manual search of the reference lists of the retrieved papers by two investigators (G.P. and B.B.). Abstracts of papers identified through these two steps were then screened for eligibility, and papers surviving this screening were assessed for eligibility based on a full-text reading. Discrepancies were resolved through consensus with a third author (A.D.), and eventually, Delphi rounds with all other authors. The protocol for this review has been registered in the international prospective register of systematic reviews (PROSPERO registration number CRD42020158692).

\section{Inclusion and exclusion criteria}

Papers were included if dealing with consent to treatment or research, in patients affected by MCI. We excluded papers written in languages other than English, Italian, Greek, Hebrew, or Spanish, reviews, retrospective studies, or case reports, and those papers whose full text was unavailable even after contacting the corresponding author.

\section{Data extraction (selection and coding)}

Titles and abstracts were screened by two reviewers independently, in duplicate, to determine whether retrieved studies met the above-outlined inclusion criteria.

Full texts were obtained for studies apparently meeting inclusion criteria or where a decision could not be made from the title and/or abstract alone, for a detailed review against inclusion criteria. Full-texts were independently assessed for eligibility by two reviewers. Discrepancies were resolved by an initial discussion with a third reviewer, when required, and possibly, with Delphi rounds, until complete consensus was reached.

A standardized form was used to extract data from the included studies to assist in study quality and evidence synthesis. Extracted information included: the focus of the study, participant characteristics, screening tools/neuropsychological assessments performed, the decisional ability construct the authors were referring to, the criterion used to validate the final judgment (capable/incapable), and authors conclusions, as well as information required for assessment of the risk of bias. Extraction was completed by two reviewers independently, in duplicate. A third reviewer was consulted when needed.

\section{Quality evaluation}

The assessment of observational study quality was conducted using the Newcastle-Ottawa scale (NOS) (Deeks et al., 2003). Two reviewers independently assessed the methodological quality of the studies using the NOS for case-control study in three domains: (1) subject selection: a score of $0-4,(2)$ comparability of the case and control groups: a score of $0-2$, and (3) the ascertainment of either the exposure or outcome of interest: a score of 0-3 (Deeks et al., 2003). Disagreements were resolved through Delphi rounds until full consensus was reached.

\section{Statistical analyses}

The Review Manager software version 5.2 (Copenhagen: The Nordic Cochrane Centre, The Cochrane Collaboration) and the Comprehensive MetaAnalysis software version 2 (Biostat, Inc., Englewood, New Jersey, USA) were used to perform the meta-analysis. We performed four meta-analyses to examine the psychometric properties of the tools used to assess decisional capacity to consent to treatment or research, including Understanding, Reasoning, Appreciation, and Expression of a Choice. The Cochran's $Q$-statistic test and the $I^{2}$ statistic were used to evaluate the heterogeneity of the studies. A $P$-value of $Q$ text $<0.10$ or $I^{2}>50 \%$ indicated significant heterogeneity (Higgins et al., 2003). A subgroup analysis was performed on studies sharing the same decisional capacity instrument. The outcome measures from the individual studies were combined using a random-effects model. Since scores on the decisional capacity subscales were continuous data obtained from different scales (MacCAT-T, Capacity to Consent to Treatment Instrument - CCTI, MacCAT-CR, University of California Brief Assessment of Capacity to Consent - UBACC), standardized mean difference (SMD) with 95\% confidence intervals (CIs) was used to analyze the studies. We considered $P<0.05$ (two-tailed) to be statistically significant. Publication bias was tested by visually inspecting the funnel plot and performing the Egger's linear regression test. Sensitivity analysis was conducted by removing each study individually to evaluate the quality and consistency of the results.

\section{Results}

We identified 109 potentially eligible studies from 1672 records obtained from the selected databases and one from alternative sources. After reviewing the full content of the papers, 102 papers were excluded for several reasons: 49 did not investigate the capacity to consent to treatment or research, 26 were case descriptions, editorials, or reviews, 16 examined a different population or did not provide data separately for MCI, 7 did not provide the needed data, even after their authors were contacted, and 4 contained duplicate data. The process 


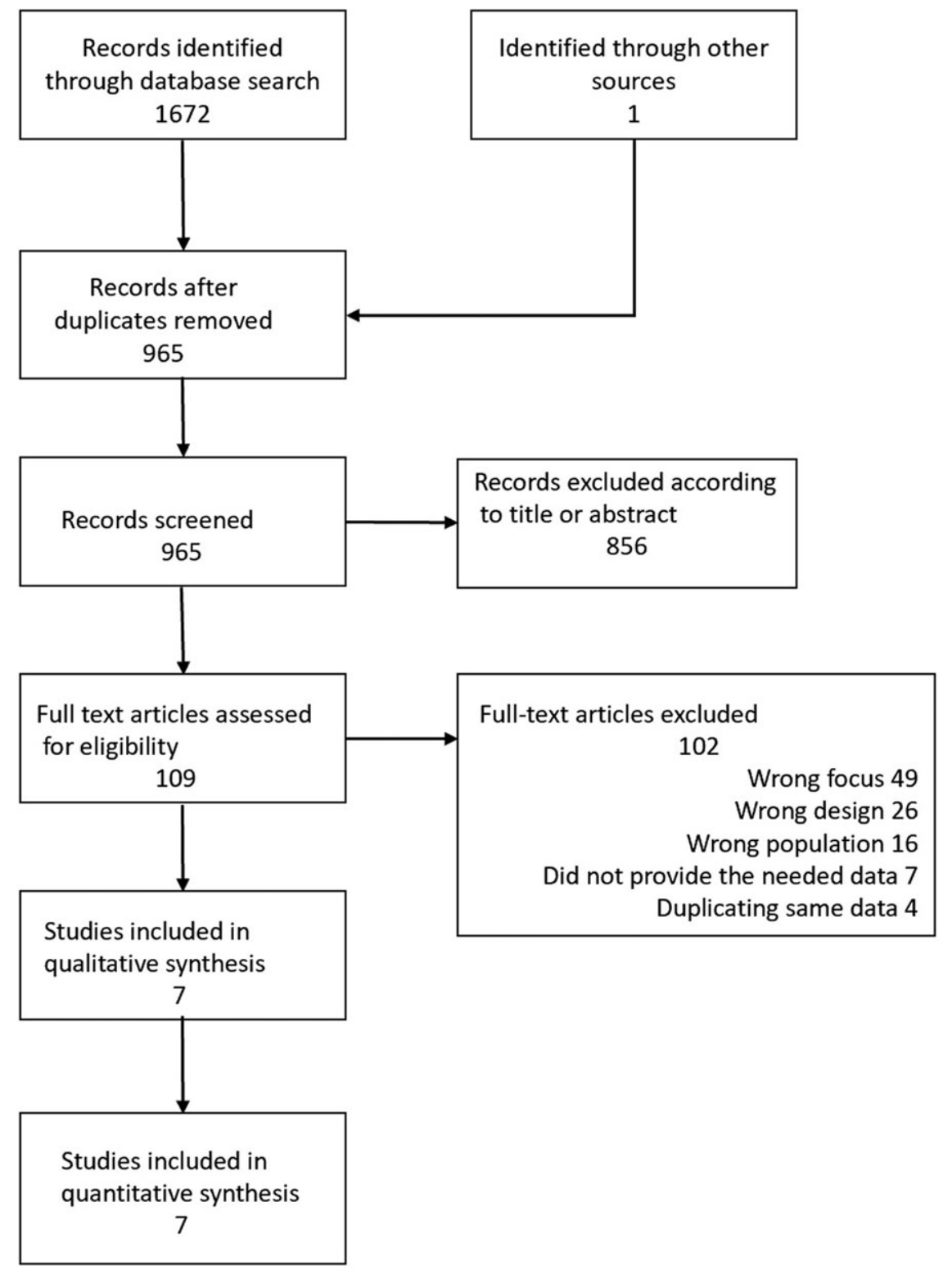

Figure 1. The flow diagram of the study screening, conducted according to the PRISMA guidelines.

of identifying eligible studies is outlined in Figure 1. For the list of the excluded studies see the Supplementary Data file published as supplementary material online attached to the electronic version of this paper.

\section{Studies, participants, and treatment characteristics}

The characteristics of the included studies are summarized in Table 1. Of the seven studies, one study used the MacCAT-CR (Jefferson et al., 2008), one used the UBACC (Duron et al., 2013), three studies used the CCTI (Griffith et al., 2010; Okonkwo et al., 2007; 2008b), and two studies used the MacCAT-T (Lui et al., 2012; Oshima et al., 2020).
The MacCAT-T is a semi-structured interview that assesses the main facets of treatment-related decisionmaking, reflecting commonly applied legal standards for competence to consent to treatment. The subscales investigate the understanding of the disclosed information about the disorder and the treatment's main features, as well as presumed associated risks and benefits (rated 0-6); appreciation, i.e. the patient's ability to appreciate his/her own diagnosis and treatment (rated 0-4); the patient's reasoning ability, including consequential and comparative thinking, and logical consistency (rated 0-8); and the ability to clearly express a choice (rated 0-2). In the included studies it was used to assess the capacity of subjects to consent to medical treatment, based on a hypothetical situation (Lui et al., 2012) and hypothetical vignettes (Oshima et al., 2020). 
Table 1. Studies on decisional capacity to consent to treatment or research

\begin{tabular}{|c|c|c|c|c|c|c|c|c|c|}
\hline AUTHOR & FOCUS OF STUDY & POPULATION & $\begin{array}{c}\text { AGE } \\
(M E A N \pm S D)\end{array}$ & MMSE & EDUCATION & $\begin{array}{l}\text { DECISIONAL } \\
\text { ABILITIES } \\
\text { CONSTRUCT }\end{array}$ & INSTRUMENT & $\begin{array}{l}\text { CRITERION } \\
\text { VALIDATION }\end{array}$ & MAIN FINDING \\
\hline $\begin{array}{l}\text { Griffith et al., } \\
\quad 2010\end{array}$ & $\begin{array}{l}\text { Finding brain metabolic } \\
\text { correlates of treatment } \\
\text { decision-making }\end{array}$ & $\begin{array}{l}\mathrm{aMCI}=29 \\
\mathrm{HC}=42\end{array}$ & $\begin{array}{l}70.31 \pm 7.00 \\
64.83 \pm 8.34\end{array}$ & $\begin{array}{l}28.00 \pm 1.44 \\
29.43 \pm 1.04\end{array}$ & $\begin{array}{l}14.00 \pm 2.84 \\
15.00 \pm 2.27\end{array}$ & $\begin{array}{l}\text { Choice } \\
\text { Reasonableness } \\
\text { Appreciation } \\
\text { Rational reasons } \\
\text { Understanding }\end{array}$ & CCTI & N/A & $\begin{array}{l}\text { In the aMCI, the NAA/ } \\
\text { Cr ratio was posi- } \\
\text { tively correlated with } \\
\text { rational reasons }\end{array}$ \\
\hline $\begin{array}{l}\text { Lui et al., } \\
\qquad 2012^{*}\end{array}$ & $\begin{array}{l}\text { Assessment of decisional } \\
\text { capacity to consent to } \\
\text { treatment }\end{array}$ & $\begin{array}{l}\mathrm{aMCI}=99 \\
\mathrm{AD}=95 \\
\mathrm{HC}=97\end{array}$ & $\begin{array}{l}78.2 \pm 7.0 \\
82.3 \pm 6.6 \\
74.2 \pm 6.5\end{array}$ & $\begin{array}{l}25.3 \pm 2.5 \\
19.5 \pm 2.7 \\
26.6 \pm 2.4\end{array}$ & $\begin{array}{l}3.2 \pm 3.5 \\
1.6 \pm 3.3 \\
4.3 \pm 3.7\end{array}$ & $\begin{array}{l}\text { Understanding } \\
\text { Appreciation } \\
\text { Reasoning } \\
\text { Expressing a choice }\end{array}$ & MacCAT-T & $\begin{array}{l}\text { Clinicians } \\
\text { ratings }\end{array}$ & $\begin{array}{l}\text { Decisional capacity is } \\
\text { impaired before the } \\
\text { diagnosis of } \\
\text { dementia is made }\end{array}$ \\
\hline $\begin{array}{l}\text { Okonkwo } \\
\text { et al., } \\
2007^{* *}\end{array}$ & $\begin{array}{l}\text { Assessment of decisional } \\
\text { capacity to consent to } \\
\text { treatment }\end{array}$ & $\begin{array}{l}\mathrm{aMCI}=60 \\
\mathrm{AD}=31 \\
\mathrm{HC}=56\end{array}$ & $\begin{array}{l}68.05 \pm 6.77 \\
74.45 \pm 8.59 \\
64.63 \pm 8.50\end{array}$ & $\begin{array}{l}28.37 \pm 1.50 \\
24.81 \pm 2.97 \\
29.55 \pm 0.76\end{array}$ & $\begin{array}{l}14.87 \pm 3.14 \\
13.26 \pm 3.07 \\
15.23 \pm 2.37\end{array}$ & $\begin{array}{l}\text { Choice } \\
\text { Reasonableness } \\
\text { Appreciation } \\
\text { Rational reasons } \\
\text { Understanding }\end{array}$ & CCTI & N/A & $\begin{array}{l}\text { MCI demonstrate sig- } \\
\text { nificant impairments } \\
\text { on capacity to con- } \\
\text { sent to treatment }\end{array}$ \\
\hline $\begin{array}{l}\text { Okonkwo } \\
\text { et al., } \\
\text { 2008a; } \\
2008 \mathrm{~b}\end{array}$ & $\begin{array}{l}\text { Assessment of the } \\
\text { longitudinal change } \\
\text { in MCI treatment } \\
\text { decision-making } \\
\text { capacity }\end{array}$ & $\begin{array}{l}\mathrm{MCI}=116 \\
\mathrm{HC}=88\end{array}$ & $\begin{array}{l}70.54 \pm 7.21 \\
67.05 \pm 8.33\end{array}$ & $\begin{array}{l}28.03 \pm 1.93 \\
29.43 \pm 0.95\end{array}$ & $\begin{array}{l}14.54 \pm 3.26 \\
14.99 \pm 2.39\end{array}$ & $\begin{array}{l}\text { Choice } \\
\text { Reasonableness } \\
\text { Appreciation } \\
\text { Rational reasons } \\
\text { Understanding }\end{array}$ & CCTI & N/A & $\begin{array}{l}\text { Over a period of } 3 \text { years, } \\
\text { patients with aMCI } \\
\text { have a progressive } \\
\text { decline in capacity to } \\
\text { consent to treatment }\end{array}$ \\
\hline $\begin{array}{l}\text { Oshima et al., } \\
2020\end{array}$ & $\begin{array}{l}\text { Assessment of decisional } \\
\text { capacity to consent to } \\
\text { treatment }\end{array}$ & $\begin{array}{l}\mathrm{MCI}=40 \\
\mathrm{HC}=33\end{array}$ & $\begin{array}{l}76.7 \pm 7.8 \\
68.8 \pm 8.7\end{array}$ & $\begin{array}{l}25.7 \pm 2.8 \\
29.2 \pm 1.2\end{array}$ & $\begin{array}{l}12.7 \pm 2.7 \\
12.8 \pm 2.5\end{array}$ & $\begin{array}{l}\text { Understanding } \\
\text { Appreciation } \\
\text { Reasoning } \\
\text { Expressing a choice }\end{array}$ & MacCAT-T & $\begin{array}{l}\text { Clinicians } \\
\text { rating }\end{array}$ & $\begin{array}{l}\text { Clinicians tend to } \\
\text { overestimate MCI } \\
\text { patients' competency }\end{array}$ \\
\hline $\begin{array}{l}\text { Duron et al., } \\
2013\end{array}$ & Instrument validation & $\begin{array}{l}\mathrm{MCI}=26 \\
\mathrm{AD}=33 \\
\mathrm{HC}=12\end{array}$ & $\begin{array}{l}79.9 \pm 5.4 \\
83.2 \pm 7.8 \\
78.0 \pm 6.5\end{array}$ & $\begin{array}{l}27.9 \pm 2.1 \\
21.3 \pm 5.5 \\
28.3 \pm 1.8\end{array}$ & $\begin{array}{c}\text { N/A (non ci } \\
\text { sono le medie) }\end{array}$ & Understanding & UBACC & Cut-off & $\begin{array}{l}\text { The UBACC scale was } \\
\text { accurate in the as- } \\
\text { sessment of decisio- } \\
\text { nal capacity to } \\
\text { consent to research } \\
\text { of cognitively } \\
\text { impaired populations }\end{array}$ \\
\hline $\begin{array}{l}\text { Jefferson } \\
\text { et al., } \\
2008^{* * *}\end{array}$ & $\begin{array}{l}\text { Assessment of decisional } \\
\text { capacity to consent to } \\
\text { research and its neu- } \\
\text { rological correlates }\end{array}$ & $\begin{array}{l}\mathrm{MCI}=40 \\
\mathrm{HC}=40\end{array}$ & $\begin{array}{l}74.3 \pm 7.5 \\
72.3 \pm 5.5\end{array}$ & $\begin{array}{l}27.8 \pm 1.8 \\
29.3 \pm 0.9\end{array}$ & $\begin{array}{l}15.8 \pm 2.9 \\
16.5 \pm 2.5\end{array}$ & $\begin{array}{l}\text { Understanding } \\
\text { Appreciation } \\
\text { Reasoning } \\
\text { Expressing a choice }\end{array}$ & MacCAT-CR & $\begin{array}{l}\text { Clinicians } \\
\text { ratings }\end{array}$ & $\begin{array}{l}\text { MCI demonstrate sig- } \\
\text { nificant impairments } \\
\text { on capacity to con- } \\
\text { sent to research } \\
\text { compared to controls }\end{array}$ \\
\hline
\end{tabular}


The CCTI is a vignette-based assessment measure of medical decision-making capacity, structured on five consent standards: expressing a treatment choice (S1; range: $0-4)$, making a reasonable treatment choice (S2; \%), appreciating the consequences of a treatment choice (S3; range: $0-8)$, providing rational reasons for a treatment choice (S4; range: $0-12$ ), and understanding the treatment choices ( 55 ; range: $0-78)$. However, the capacity of making a reasonable treatment choice (S2) is not a clinically accepted consent standard because of concerns about the arbitrariness of the operative term reasonable (Okonkwo et al., 2007). The CCTI consists of two clinical vignettes that each present a hypothetical medical problem (A: neoplasm, B: cardiovascular disease) and symptoms, and two treatment alternatives with associated risks and benefits.

The MacCAT-CR is a semi-structured interview, which relies on the same MacCAT-T multidimensional capacity model but comprises 21 -items assessing four abilities underlining competence to consent to clinical research: understanding of the research project's purpose, risks, potential benefits, and procedures (range 0-26); appreciation of the effect of research participation on one's own condition (range 0-6); reasoning about the consequences of participation (range 0-8); and expression of a choice in a consistent way (range 0-2). In the included study (Jefferson et al., 2008) was used to assess subjects' decision-making to consent to a hypothetical clinical trial.

The UBACC is a 10-item scale, developed as a screening instrument, and focuses on capacity to provide informed consent to a research protocol. It investigates the understanding of the research project's purpose, risks, benefits, and nature (research or treatment) (range 0-8); appreciation of the effect of research participation on one's own condition (range 0-10); and reason about the motive to participate (range $0-2$ ). Duron et al. (2013) used this instrument on a subsample of patients enrolled in a real clinical trial to assess the relationship between IGF-1 and IGFBP-3 serum levels and cognitive impairment, in a large sample of older subjects evaluated in memory clinics.

Among the included studies, only one (Griffith et al., 2010) mentioned that a portion of patients affected by MCI was taking pharmacological treatment (cholinesterase inhibitors) during the study period. Jefferson et al. (2008) referred to slightly deviate the MacCAT-CR administration from the manual (by allowing participants to retain a copy of the consent disclosure while answering all items) to enhance the ecological validity of the consent process.

A total number of 410 patients with MCI, 149 patients with $\mathrm{AD}$, and 368 healthy subjects were included. Four studies were conducted in the United States (Griffith et al., 2010; Jefferson et al., 2008;
Okonkwo et al., 2007; 2008a; 2008b), one in France (Duron et al., 2013), one in Japan (Oshima et al., 2020), and one in China (Lui et al., 2012). The mean age ranged from 68.05 to 79.9 years for the MCI patient group, from 74.45 to 83.2 years for the $\mathrm{AD}$ patient group, and from 64.63 to 78 years for the HCs. Mean years of education ranged from 3.17 to 15.8 for the MCI patient group, from 1.62 to 13.26 for the $\mathrm{AD}$ patient group, and from 4.3 to 16.5 for the HCs. The mean MMSE total score ranged from 25.3 to 28.37 for the MCI patient group, from 19.5 to 24.81 for the $\mathrm{AD}$ patient group, and from 26.6 to 29.55 for the HCs.

\section{Quality evaluation}

The NOS scores of the seven studies ranged from five to four points (Table 2). Patients from four out of seven studies had adequate definitions with independent validation. Four studies performed an independent decisional capacity evaluation by a physician blind to capacity assessment (Duron et al., 2013; Jefferson et al., 2008; Lui et al., 2012; Oshima et al., 2020). Reasons for increased bias included inadequate representativeness of patients (no study enrolled consecutive patients), and the lack of age- and education-matching between patients with MCI, $\mathrm{AD}$, and HCs.

\section{Decision-making capacity in Mild Cognitive Impairment}

A total number of 410 patients with MCI and $368 \mathrm{HCs}$ from 7 studies were compared on Understanding scores. Using random-effects models, patients scored significantly lower on Understanding $(\mathrm{SMD}=-1.13$, $95 \%$ CI: -1.41 to $-0.84, P<0.001 ; I^{2}=67 \%$, $P=0.006)$. Due to subscale heterogeneity, a sensitivity analysis was conducted; we detected a significant decrease in the Understanding subscale score of patients with MCI compared with their control counterparts $(\mathrm{SMD}=-1.04,95 \% \mathrm{CI}:-1.31$ to -0.77 , $P<0.001 ; I^{2}=52 \%, P=0.07$, Figure $\left.2 \mathrm{~A}\right)$.

A total number of 384 patients with MCI and 356 healthy subjects from 6 studies were compared on the scores of Appreciating, Reasoning, and Expression of a choice. Using random-effects models, patients scored significantly lower on Appreciating $(\mathrm{SMD}=-0.51$, 95\% CI: -0.66 to $-0.36, \quad P<0.001 ; \quad I^{2}=0 \%$, $P=0.97)$, and on Reasoning $(\mathrm{SMD}=-0.62,95 \%$ CI: $-0.77,-0.47, P<0.001 ; I^{2}=0 \%, P=0.46$ ), but no significant differences were found in the Expression of a Choice subscale $(\mathrm{SMD}=-0.19,95 \% \mathrm{CI}$ : $\left.0.52,0.14, P=0.27 ; I^{2}=77 \%, P=0.002\right)$, compared with the control group (Figures 2B, 2C and 2D).

To overcome the limitations of comparing studies using different decisional capacity measures, we performed a subgroup analysis on 205 patients with MCI 
Table 2. Quality assessment through the Newcastle-Ottawa scale (NOS)

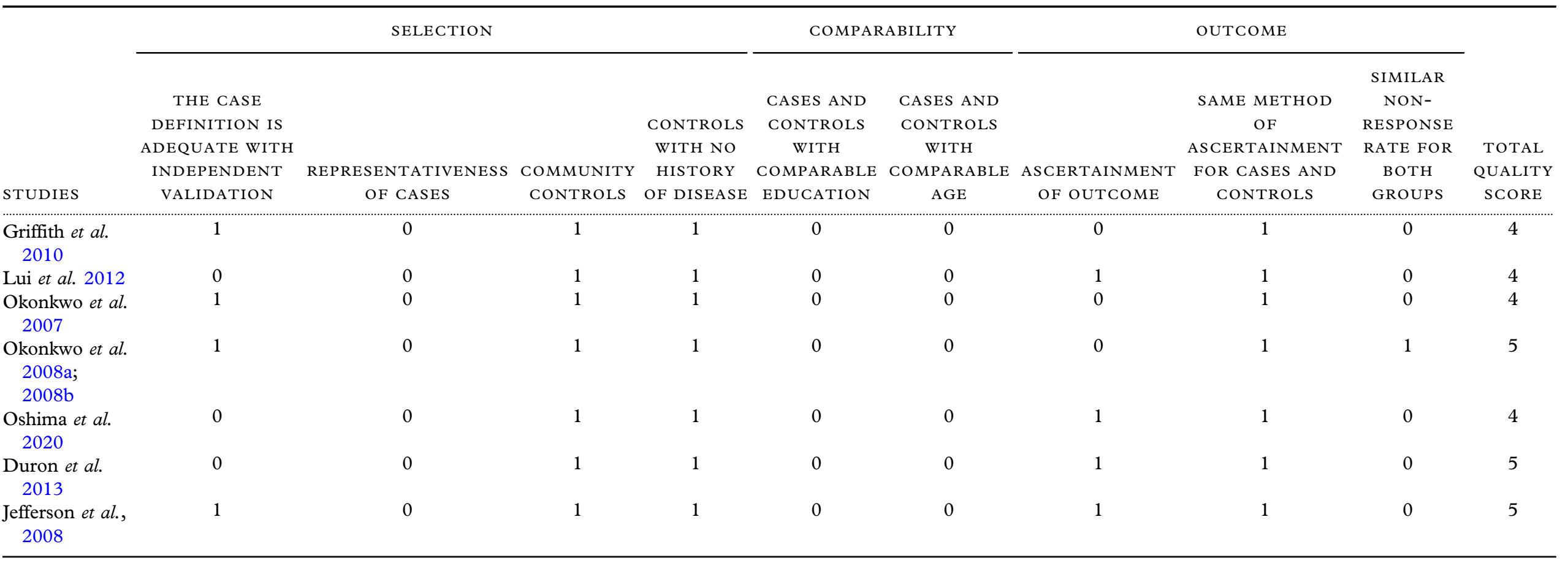


(A) Understanding

\begin{tabular}{|c|c|c|c|c|c|c|c|c|c|c|c|c|}
\hline \multirow[b]{2}{*}{ Study or Subgroup } & \multicolumn{3}{|c|}{$\mathrm{MCl}$} & \multicolumn{3}{|c|}{ Controls } & \multicolumn{3}{|c|}{ Std. Mean Difference } & \multirow{2}{*}{\multicolumn{3}{|c|}{$\begin{array}{l}\text { Std. Mean Difference } \\
\text { IV, Random, } 95 \% \mathrm{CI}\end{array}$}} \\
\hline & Mean & SD & Total & Mean & SD & Total & Weight & IV, Random, $95 \% \mathrm{Cl}$ & Year & & & \\
\hline Okonkwo 2007 & 49.78 & 12.6 & 60 & 62.61 & 8.32 & 56 & $19.4 \%$ & $-1.19[-1.58,-0.79]$ & 2007 & $\rightarrow-$ & & \\
\hline Okonkwo 2008 & 47.56 & 12.17 & 116 & 63.4 & 8.08 & 88 & $0.0 \%$ & $-1.49[-1.80,-1.18]$ & 2008 & & & \\
\hline Jefferson 2008 & 21.3 & 3.2 & 40 & 24.2 & 1.7 & 40 & $16.4 \%$ & $-1.12[-1.59,-0.65]$ & 2008 & & & \\
\hline Griffith 2010 & 46.93 & 12.93 & 29 & 63.9 & 9.12 & 42 & $14.2 \%$ & $-1.55[-2.09,-1.01]$ & 2010 & & & \\
\hline Lui 2012 & 4.8 & 0.8 & 99 & 5.3 & 0.7 & 97 & $24.2 \%$ & $-0.66[-0.95,-0.37]$ & 2012 & - 땀- & & \\
\hline Duron 2013 & 16.9 & 2.5 & 26 & 19 & 0.7 & 12 & $9.8 \%$ & $-0.97[-1.69,-0.25]$ & 2013 & & & \\
\hline Oshima 2020 & 3.42 & 1.27 & 40 & 4.44 & 0.78 & 33 & $16.0 \%$ & $-0.94[-1.42,-0.45]$ & 2020 & & & \\
\hline Total $(95 \% \mathrm{Cl})$ & & & 294 & & & 280 & $100.0 \%$ & $-1.04[-1.31,-0.77]$ & & & & \\
\hline $\begin{array}{l}\text { Heterogeneity: } \operatorname{Tau}^{2}= \\
\text { Test for overall effect: }\end{array}$ & $\begin{array}{l}0.06: C h \\
Z=7.60\end{array}$ & $\begin{array}{l}i^{2}=10 . \\
(P<0 .\end{array}$ & $\begin{array}{l}36, d f= \\
00001)\end{array}$ & $5(P=$ & $0.07):$ & $l^{2}=52^{\circ}$ & & & & $\begin{array}{cc}-2 & -1 \\
\text { Favors [MCI] }\end{array}$ & $\begin{array}{cc}0 & 1 \\
\text { Favors [C }\end{array}$ & $\begin{array}{c}2 \\
\text { Controls] }\end{array}$ \\
\hline
\end{tabular}

(B) Appreciating

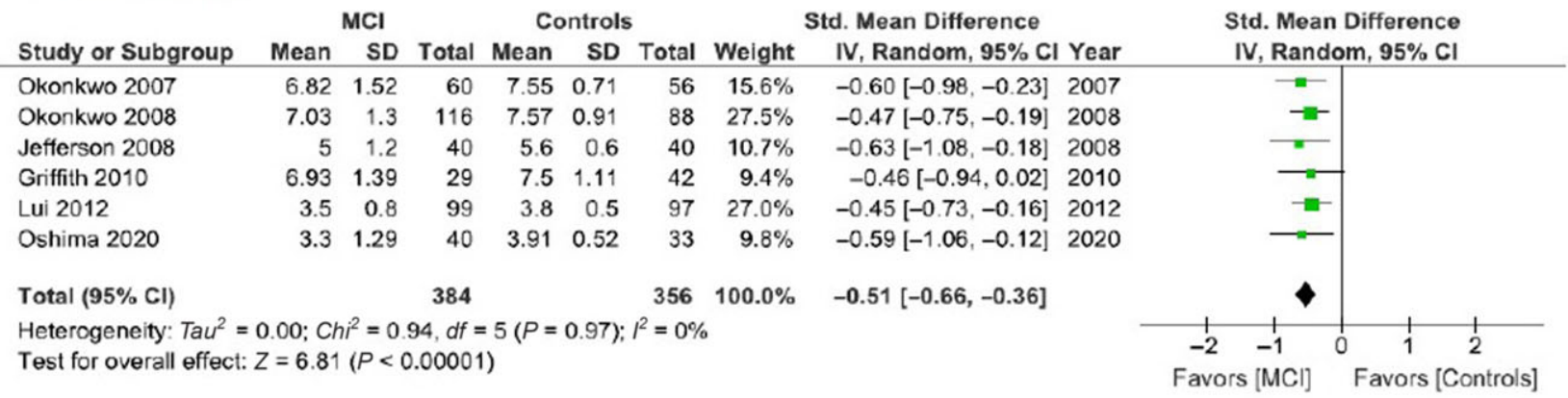

(C) Reasoning

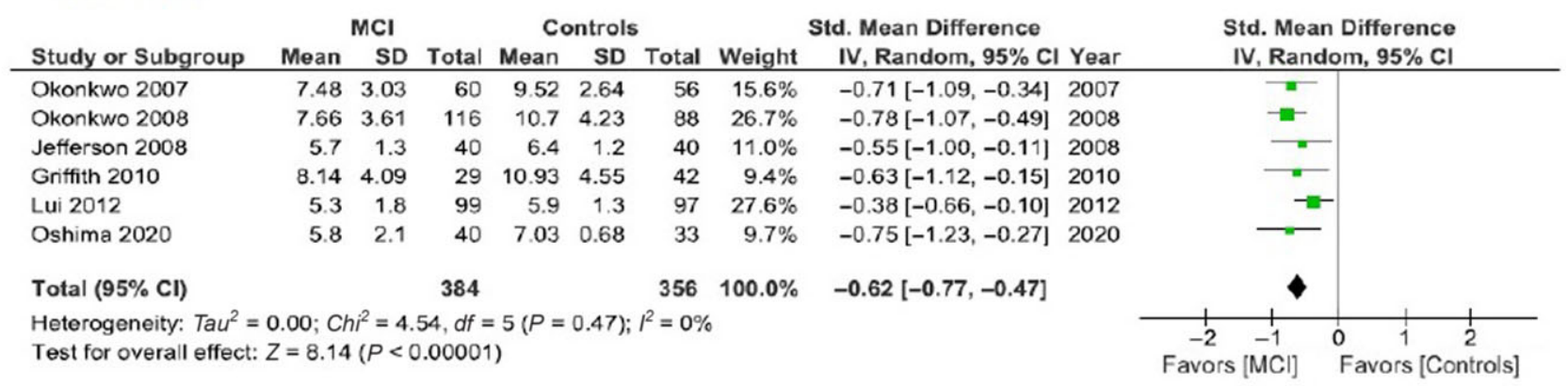

(D) Expressing a choice

\begin{tabular}{|c|c|c|c|c|c|c|c|c|c|c|c|}
\hline \multirow[b]{2}{*}{ Study or Subgroup } & \multicolumn{3}{|c|}{$\mathrm{MCl}$} & \multicolumn{3}{|c|}{ Controls } & \multicolumn{3}{|c|}{ Std. Mean Difference } & \multirow{2}{*}{$\begin{array}{r}\text { Std. Mean Difference } \\
\text { IV, Random, } 95 \% \mathrm{CI}\end{array}$} & \\
\hline & Mean & SD & Total & Mean & SD & Total & Weight & IV, Random, $95 \% \mathrm{Cl}$ & Year & & \\
\hline Okonkwo 2007 & 3.88 & 0.56 & 60 & 3.88 & 0.38 & 56 & $20.1 \%$ & $0.00[-0.36,0.36]$ & 2007 & & \\
\hline Okonkwo 2008 & 3.87 & 0.49 & 116 & 3.88 & 0.37 & 88 & $22.5 \%$ & $-0.02[-0.30,0.25]$ & 2008 & & \\
\hline Jefferson 2008 & 1.9 & 0.3 & 40 & 2 & 0.2 & 40 & $18.0 \%$ & $-0.39[-0.83,0.05]$ & 2008 & & \\
\hline Griffith 2010 & 3.86 & 0.35 & 29 & 3.76 & 0.48 & 42 & $17.2 \%$ & $0.23[-0.25,0.70]$ & 2010 & & \\
\hline Lui 2012 & 1.8 & 0.4 & 99 & 2 & 0.1 & 97 & $22.2 \%$ & $-0.68[-0.97,-0.39]$ & 2012 & - & \\
\hline Oshima 2020 & 1.93 & 0.47 & 40 & 2 & 0 & 33 & & Not estimable & 2020 & & \\
\hline Total $(95 \% \mathrm{CI})$ & & & 384 & & & 356 & $100.0 \%$ & $-0.19[-0.52,0.14]$ & & & \\
\hline $\begin{array}{l}\text { Heterogeneity: } \mathrm{Tau}^{2}= \\
\text { Test for overall effect }\end{array}$ & $\begin{array}{l}0.11 ; C h \\
Z=1.11\end{array}$ & $\begin{array}{l}i^{2}=1 \\
(P=\end{array}$ & $\begin{array}{l}.14, d f \\
.27)\end{array}$ & $=4(P$ & $=0.002$ & 2) $; 1^{2}=$ & $77 \%$ & & & $\begin{array}{cc}1 & 1 \\
-2 & -1 \\
\text { Favors } & {[\mathrm{MCl}]}\end{array}$ & $\begin{array}{c}2 \\
\text { Sontrols] }\end{array}$ \\
\hline
\end{tabular}

Figure 2. Meta-analysis of the standardized mean difference in Understanding (A), Appreciating (B), Reasoning (C) and Expressing a choice (D) of patients with $\mathrm{MCl}$ versus $\mathrm{HCS}$.

and 186 healthy subjects from 3 studies that used the same instrument (CCTI) on the score of Understanding, Appreciating, Reasoning, and Expression of a choice. Using random-effect models, patients scored significantly lower on Understanding $(\mathrm{MD}=-15.12$, $95 \%$ CI: -17.24 to $-13, P<0.001 ; I^{2}=2 \%$, $P=0.36)$, on Appreciating ( $\mathrm{MD}=-0.60 ; 95 \% \mathrm{CI}$ : -0.83 to $\left.-0.37, P<0.001 ; I^{2}=0 \%, P=0.77\right)$, and on 


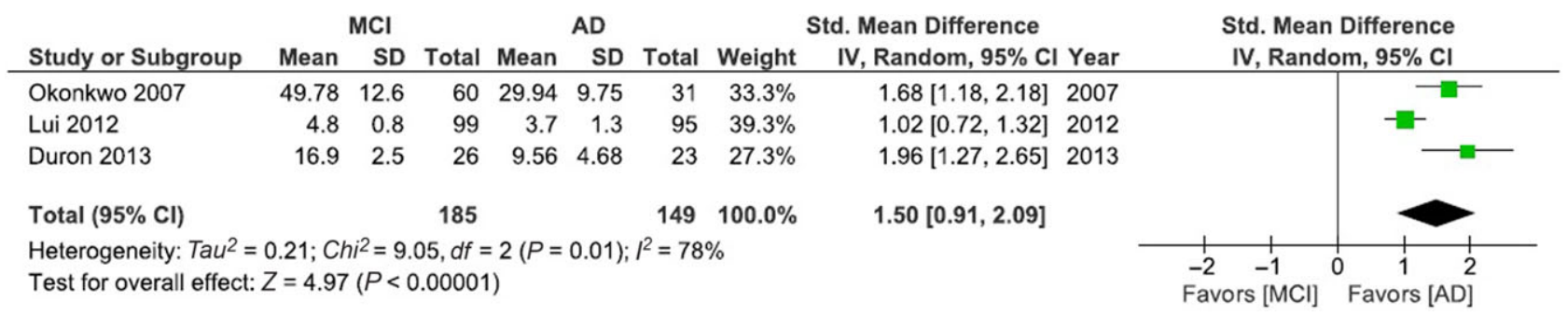

Figure 3. Meta-analysis of the standardized mean difference in Understanding of patients with MCI versus AD.

Reasoning $(\mathrm{MD}=-2.54,95 \% \mathrm{CI}:-3.25$ to -1.84 , $P<0.001 ; I^{2}=0 \%, P=0.42$ ), but no significant differences were found in the Expression of a Choice subscale $(\mathrm{MD}=0.01 ; 95 \% \mathrm{CI}:-0.07$ to $0.10, P=0.74$; $I^{2}=0 \%, P=0.62$ ) compared with the HC group (see Figure $S 1$ published as supplementary material online attached to the electronic version of this paper.

A total number of 185 patients with MCI and 149 patients with $\mathrm{AD}$ from 3 studies were compared on their scores on Understanding. Using random-effects models, patients with $\mathrm{AD}$ scored significantly lower on Understanding $(\mathrm{SMD}=1.50,95 \% \mathrm{CI}: 0.91$, $2.09, P=0.01, I^{2}=78 \%, P=0.001$; Figure 3).

Due to the dearth of available data, further analysis could not be conducted to identify which clinical, demographic, and treatment-related variables were associated with informed consent to treatment and research in patients with MCI.

\section{Publication bias and sensitivity analysis}

Visual inspection of the funnel plot and the Egger's regression test did not show any publication bias for the subscales of Understanding $(t=0.50 ; P=0.64)$, Appreciation $(t=1,739 ; \quad P=0.157)$, Reasoning $(t=0.538 ; P=0.619)$, and Expression of a Choice $(t=0.64 ; P=0.567)$ in the comparison between patients affected by MCI and HCs. Similarly, the Egger's regression test did not show any publication bias for the subscale of Understanding $(t=5.725$; $P=0.11)$ in the comparison between patients with $\mathrm{MCI}$ and with AD. However, we should be cautious in excluding the presence of publication bias, considering the low statistical power of the test in a meta-analysis based on a limited number of trials (Eggers et al., 1997; Higgins et al., 2020). After removing each study one by one, the results were not altered compared to the primary analysis, suggesting the consistency of the results.

\section{Discussion}

This meta-analysis of seven studies showed significantly lower scores in capacity to consent to treatment and research in patients with MCI compared to HCs in understanding, appreciating, and reasoning, while they scored significantly higher compared to $\mathrm{AD}$ patients on understanding. The magnitude of the effects was medium to large across different decisional capacity subscales. Regarding the Understanding subscale, the confidence in the estimate of the effect is moderate despite the large effect size because of some inconsistency due to the moderate and high degree of heterogeneity between studies in the comparison between patients with MCI and $\mathrm{HC}$ and with MCI and with $\mathrm{AD}$, respectively. Overall, our review is consistent with impaired decision-making in patients with MCI (Appelbaum, 2010; Griffith et al., 2010; Han et al., 2015; Jefferson et al., 2008; 2012; Lui et al., 2012; Mittal et al., 2007; Okonkwo et al., 2007; 2008a; 2008b; Simpson, 2010), and highlights the need for accurate and efficient capacity evaluations in this vulnerable group of patients. Patients with MCI are increasingly treated with dementia-related medications and are also often involved in clinical trials, and the assessment of their decisional capacity to consent to treatment or research can represent a challenge for physicians who tend to rely on their clinical judgment. For example, a study by Marson et al. (1997) found that the achieved agreement among five physicians who reviewed videotapes of capacity assessments and rated the competence of patients with mild $\mathrm{AD}$, without the use of any systematic and structured interview, was not better than chance (kappa statistic, 0.14). A recent study by Oshima et al. (2020) found that clinicians tend to overestimate MCI patients' competence to consent to treatment. This is an issue that needs to be addressed, considering that treatment or research in the absence of informed consent, except in an emergency or exceptional circumstance contrasts with the principle of autonomy and may determine physician professional liability issues (Appelbaum, 2010). Moreover, the elevated risk for reduced decisional capacity in elderly patients affected by cognitive impairment often raises uncertainty as to whether they can provide valid consent or consent must be obtained from a substitute decisionmaker (Appelbaum, 2010).

Regarding decisional capacity to consent to research, S. Y. Kim (2011) suggested introducing the concept of authenticity, referring to the congruence between a person's values (including beliefs, 
commitments, and relationships) and his/her decision. According to this author, in contrast to an autonomous decision, which can only be made by the patient, a decision can be authentic even when made by a surrogate, because authenticity does not require an intact capacity for self-determination, but only that the decision conforms to the individual's values.

Although decisional capacity is negatively associated with executive and cognitive dysfunctions, to date, empirical literature does not provide a basis for drawing firm conclusions about the role of specific cognitive domains on specific aspects of healthcare decision-making (Palmer and Harmell, 2016). Despite the strong correlation reported between cognitive abilities and decisional capacity components, no clear pattern of differential association has emerged (Palmer and Harmell, 2016). Specifically, the Understanding subscale has shown associations with episodic memory (Okonkwo et al., 2008a; Palmer et al., 2004), executive functioning (Dymek et al., 2001; Mandarelli et al., 2012), verbal memory, and phonemic fluency (Gerstenecker et al., 2015), and between processing speed and episodic memory (Okonkwo et al., 2008a; 2008b). Regarding the Appreciation subscale, correlations have been reported for working memory (Palmer et al., 2004), processing speed (Okonkwo et al., 2008a; 2008b), and episodic memory (Okonkwo et al., 2008a; 2008b). Finally, the Reasoning subscale showed associations with working memory (Moye and Karel, 1999; Palmer et al., 2004), and executive functions (Dymek et al., 2001; Marson et al., 1996). Further studies are needed to understand which cognitive functions are associated with the decisional capacity to consent to treatment and research. This is a topic that needs to be addressed because it would allow the suggestion of supplementary tools to evaluate patients' competency as well as to develop targeted interventions to enhance patients' decision-making.

To avoid depriving patients of their right to make healthcare decisions, it has been suggested to maximize patients' decisional capacity through several means, like conducting the clinical evaluation in the patient's native language, detecting and addressing potentially treatable conditions associated with impaired capacity (such as fever, sedation, dehydration, depression, and anxiety) before obtaining consent; by manipulating the environment where assessment occurs (for example, by performing the evaluation in quiet places to avoid distractions or by assessing patients affected by mild dementia early in the day to avoid sundowning), by enhancing the informed consent process to make the decisional task easier (Appelbaum, 2010).

Among the above-mentioned strategies, a promising field of research, regrettably neglected, is represented by the possibility to enhance informed consent by compensating for cognitive deficits. In fact, to the best of our knowledge, studies aimed at improving decisional capacity to consent to research in $\mathrm{AD}$ and $\mathrm{MCI}$ are few and have led to contrasting results (Mittal et al., 2007; Palmer et al., 2018; Rubright et al., 2010). A study on the use of multimedia disclosure and cognitive feedback to improve decisional capacity to consent to research among patients with $\mathrm{AD}$ and non-psychiatric comparison participants found no significant effect of the enhanced consent procedure relative to the routine consent (Palmer et al., 2018). Another study comparing two enhanced consent procedures (a PowerPoint presentation and an enhanced printed consent form) in patients with $\mathrm{AD}$ and $\mathrm{MCI}$ found an improvement in patients' understanding of both conditions (Mittal et al., 2007). However, the small sample size of this study (19 patients with $\mathrm{AD}$ and 16 with $\mathrm{MCI}$ ) and the absence of a routine consent comparison condition prevent the generalization of its results. Finally, a study by Rubright and colleagues (2010), employing a memory and organizational aid added to a standard consent procedure, found an improvement in capacity to consent to research in patients with $\mathrm{AD}$. Moreover, to the best of our knowledge, to date, there is no study that has specifically tested the efficacy of a specific cognitive training aimed at enhancing decisional capacity in informed consent to treatment or research participation. We deem that this a gap that needs to be addressed, especially for those patients whose decisional capacity, although not yet deeply compromised, may benefit from the support and enhancing interventions. This view is also supported by the UN Convention on the Rights of Persons with Disabilities (CRPD; UN General Assembly, 2006) that holds that the full and equal enjoyment of legal capacity for disabled people requires a shift to supported decision-making paradigms and the abolition of substituted decision-making that allows forced treatment (Craigie, 2015; Craigie et al., 2019; Szmukler and Bach, 2015; Szmukler et al., 2014).

\section{Limitations}

Several limitations need to be acknowledged. First, the sample sizes of the included studies as well as the overall sample were relatively small, the studies were all observational and with a moderate risk of bias. Second, due to the dearth of studies, we pooled together studies using different tools and evaluating capacity to consent to treatment and capacity to consent to research. This was possible because, despite their different capacity thresholds, these are very similar concepts and refer to the same four dimensions (understanding, appreciating, reasoning, and expressing a choice). However, some differences need to be acknowledged. For 
example, the UBACC has been developed as a screening instrument and employs just one item to assess reasoning; the MacCAT-T and the MacCAT-CR differ in the appreciation dimension as the possibility to quit the research at any time and without consequences is a central aspect. In addition, a study comparing the agreement between three treatment decisional capacity assessment instruments (MacCAT-T, CCTI, HCAI) in mild-to-moderate dementia found a fair agreement for overall capacity and very good for understanding, while poor for Appreciating, Reasoning, and Expression of a choice (Gurrera et al., 2007). Finally, considering that four different tools for assessing patients' decisional capacity were used across studies, we used random-effects models and effect size of SMDs.

With these caveats in mind, we deem that our study raises awareness and prompts clinicians and researchers to pay more attention to decisional capacity to consent to treatment or research of patients affected by MCI.

\section{Conflict of interests}

All authors declare to have no conflict of interest regarding this work.

\section{Source of funding}

This work did not receive private or public grants or funds.

\section{Description of authors' roles}

G. Parmigiani, G. Mandarelli, and S. Ferracuti designed the study, G. Parmigiani and B. Barchielli reviewed the selected papers and rated the risk of bias, G. Kotzalidis, F. D'Antonio, A. Di Vita, and C. de Lena reviewed the literature and organized them. G. Parmigiani and A. Del Casale were responsible for carrying out the statistical analysis. All authors drafted the article and critically reviewed it. All contributing authors have read and approved the final version of the manuscript.

\section{Acknowledgments}

We gratefully acknowledge the contribution of Ms Mimma Ariano, Ms Ales Casciaro, Ms Teresa Prioreschi, and Ms Susanna Rospo, Librarians of the Sant'Andrea Hospital, School of Medicine and Psychology, Sapienza University, Rome, for rendering precious bibliographical material accessible.

\section{Supplementary material}

To view supplementary material for this article, please visit https://doi.org/10.1017/S1041610220004056

\section{References}

Appelbaum, P. S. (2007). Assessment of patients' competence to consent to treatment. The New England fournal of Medicine, 357, 1834-1840. https://doi.org/10 .1056/NEJMcp074045

Appelbaum, P. S. (2010). Consent in impaired populations. Current Neurology and Neuroscience Report, 10, 367-373. https://doi.org/10.1007/s11910-010-0123-5

Appelbaum, P. S. and Grisso, T. (2001). MacArthur Competence Assessment Tool for Clinical Research (MacCAT$C R)$. Sarasota: Professional Resource Press.

Burns, A. and Zaudig, M. (2002). Mild cognitive impairment in older people. The Lancet, 360, 1963-1965. https://doi.org/10.1016/s0140-6736(02)11920-9

Craigie, J. (2015). A fine balance: reconsidering patient autonomy in light of the UN convention on the rights of persons with disabilities. Bioethics, 29, 398-405. https://doi .org/10.1111/bioe.12133

Craigie, J., et al. (2019). Legal capacity, mental capacity and supported decision-making: report from a panel event. International fournal of Law and Psychiatry, 62, 160-168. https://doi.org/10.1016/j.ijlp.2018.09.006

Deeks, J. J. et al. (2003). Evaluating non-randomised intervention studies. Health Technology Assessment, 7, 1-173. https://doi.org/10.3310/hta7270

Dunn, L. B. and Jeste, D. V. (2001). Enhancing informed consent for research and treatment. Neuropsychopharmacology, 24(6), 595-607. https://doi.org/ 10.1016/S0893-133X(00)00218-9

Dunn, L. B., Nowrangi, M. A., Palmer, B. W., Jeste, D. V. and Saks, E. R. (2006a). Assessing decisional capacity for clinical research or treatment: a review of instruments. The American Fournal of Psychiatry, 163, 1323-1334. https:// doi.org/10.1176/ajp.2006.163.8.1323

Dunn, L. B., Palmer, B. W., Keehan, M., Jeste, D. V. and Appelbaum, P. S. (2006b). Assessment of therapeutic misconception in older schizophrenia patients with a brief instrument. The American fournal of Psychiatry, 163, 500 506. https://doi.org/10.1176/appi.ajp.163.3.500

Duron, E. et al. (2013). Capacity to consent to biomedical research's evaluation among older cognitively impaired patients. A study to validate the University of California Brief Assessment of Capacity to Consent questionnaire in French among older cognitively impaired patients. The Fournal of Nutrition, Health $\mathcal{G}$ Aging, 17, 385-389. https:// doi.org/10.1007/s12603-013-0036-5

Dymek, M. P., Atchison, P., Harrell, L. and Marson, D. C. (2001). Competency to consent to medical treatment in cognitively impaired patients with Parkinson's disease. Neurology, 56, 17-24. https://doi.org/ 10.1212/wnl.56.1.17

Egger, M., Davey Smith, G., Schneider, M. and Minder, C. (1997). Bias in meta-analysis detected by a simple, graphical test. BMF, 315: 629-634. https://doi.org/10.1136/ bmj.315.7109.629 
Gauthier, S. et al. (2006). Mild cognitive impairment. The Lancet, 367, 1262-1270. https://doi.org/10.1016/s01406736(06)68542-5

Gerstenecker, A., Meneses, K., Duff, K., Fiveash, J. B., Marson, D. C. and Triebel, K. L. (2015). Cognitive predictors of understanding treatment decisions in patients with newly diagnosed brain metastasis. Cancer, 121, 2013-2019. https://doi.org/10.1002/cncr.29326

Griffith, H. R. et al. (2010). Brain metabolic correlates of decision making in amnestic mild cognitive impairment. Neuropsychology, Development and Cognition. Section B, Aging Neuropsychology and Cognition, 17, 492-504. https:// doi.org/10.1080/13825581003646135

Grisso, T. and Appelbaum, P. S. (1998). Assessing Competence to Consent to Treatment: A Guide for Physicians and Other Health Professionals. New York: Oxford University Press.

Grisso, T., Appelbaum, P. S. and Hill-Fotouhi, C. (1997). The MacCAT-T: a clinical tool to assess patients' capacities to make treatment decisions. Psychiatric Services, 48, 1415-1419. https://doi.org/10.1176/ps.48.11.1415

Gurrera R. J., Karel M. J., Azar A. R. and Moye J. (2007). Agreement between instruments for rating treatment decisional capacity. American fournal of Geriatric Psychiatry, 15:168-173. https://doi.org/10.1097/JGP $.0 \mathrm{~b} 013 \mathrm{e} 31802 \mathrm{e} 705 \mathrm{c}$

Hamann, J. et al. (2011). Patient participation in medical and social decisions in Alzheimer's disease. Fournal of the American Geriatric Society, 59, 2045-2052. https://doi.org/ 10.1111/j.1532-5415.2011.03661.x

Han, S. D., Boyle, P. A., James, B. D., Yu, L. and Bennett, D. A. (2015). Mild cognitive impairment is associated with poorer decision-making in communitybased older persons. Fournal of the American Geriatric Society, 63, 676-683. https://doi.org/10.1111/jgs.13346

Higgins, J. P., Thompson, S. G., Deeks, J. J. and Altman, D. G. (2003). Measuring inconsistency in metaanalyses. BMF, 327, 557-560. https://doi.org/10.1136/bmj .327 .7414 .557

Higgins J. P. T. and et al. (2020). Cochrane Handbook for Systematic Reviews of Interventions version 6.1 (updated September 2020). Cochrane. Available at: https://training .cochrane.org/cochrane-handbook-systematic-reviewsinterventions; last accessed 5 November 2020

Ilhan Algin, D., Dagli Atalay, S., Ozkan, S., Ozbabalik Adapinar, D. and Ak Sivrioz, I. (2017). Memantine improves semantic memory in patients with amnestic mild cognitive impairment: a single-photon emission computed tomography study. Fournal of International Medical Research, 45, 2053-2064. https://doi.org/10.1177/0300060517715166

Janofsky, J. S., McCarthy, R. J. and Folstein, M. F. (1992). The Hopkins competency assessment test: a brief method for evaluating patient's capacity to give informed consent. Hospital and Community Psychiatry, 43, 132-136. https://doi.org/10.1176/ps.43.2.132

Jefferson, A. L. et al. (2012). Clinical research risk assessment among individuals with mild cognitive impairment. The American fournal of Geriatric Psychiatry, 20, 878-886. https://doi.org/10.1097/JGP $.0 \mathrm{~b} 013 \mathrm{e} 318252 \mathrm{e} 5 \mathrm{cb}$

Jefferson, A. L., Lambe, S., Moser, D. J., Byerly, L. K., Ozonoff, A. and Karlawish, J. H. (2008). Decisional capacity for research participation in individuals with mild cognitive impairment. Fournal of the American Geriatric Society, 56, 1236-1243. https://doi.org/10.1111/j.1532-5415.2008 $.01752 . x$

Jeste, D. V. et al. (2007). A new brief instrument for assessing decisional capacity for clinical research. Archives of General Psychiatry, 64, 966-974. https://doi.org/10.1001/ archpsyc.64.8.966

Karlawish, J. H. T., Casarett, D. J. and James, B. D. (2002). Alzheimer's disease patients' and caregivers' capacity, competency, and reasons to enroll in an earlyphase Alzheimer's disease clinical trial. Fournal of the American Geriatric Society, 50, 2019-2024. https://doi.org/ 10.1046/j.1532-5415.2002.50615.x

Kim, S. Y. (2011). The ethics of informed consent in Alzheimer disease research. Nature Reviews. Neurology, 7, 410-414. https://doi.org/10.1038/nrneurol.2011.76

Kim, S. Y., Karlawish, J. H. and Caine, E. D. (2002). Current state of research on decision-making competence of cognitively impaired elderly persons. The American fournal of Geriatric Psychiatry, 10, 151-165.

Koren, D., Poyurovsky, M., Seidman, L. J., Goldsmith, M., Wenger, S. and Klein, E. M. (2005). The neuropsychological basis of competence to consent in firstepisode schizophrenia: a pilot metacognitive study. Biological Psychiatry, 57, 609-616. https://doi.org/10.1016/ j.biopsych.2004.11.029

Lam, L. C. W., Lui, V. W. C., Chiu, H. F. K., Leung, K. F., Appelbaum, P. S., and Karlawish, J. (2013). Assessing mental capacity for everyday decision-making in the Chinese older population. Hong Kong Med F, 19(Suppl 9), 17-20.

Liberati, A. et al. (2009). The prisma statement for reporting systematic reviews and meta-analyses of studies that evaluate health care interventions: explanation and elaboration. PLoS Medicine, 6, e1000100. https://doi.org/10.1371/ journal.pmed.1000100

Lui, V. W. et al. (2012). Capacity to make decisions on medication management in Chinese older persons with mild cognitive impairment and mild Alzheimer's disease. International Psychogeriatrics, 24, 1103-1111. https://doi.org/ $10.1017 /$ S 1041610212000129

Lui, V. W., et al. (2013). Structured assessment of mental capacity to make financial decisions in Chinese olderpersons with mild cognitive impairment and mild Alzheimer disease. F Geriatr Psychiatry Neurol, 26(2), 69-77. https://doi .org/10.1177/0891988713481268

Ma, F. et al. (2017). Effects of folic acid supplementation on cognitive function and A $\beta$-related biomarkers in mild cognitive impairment: a randomized controlled trial. European Fournal of Nutrition, 58, 345-356. https://doi.org/ 10.1007/s00394-017-1598-5

Mandarelli, G. et al. (2014). Mental capacity in patients involuntarily or voluntarily receiving psychiatric treatment for an acute mental disorder. Fournal of Forensic Sciences, 59, 1002-1007. https://doi.org/10.1111/1556-4029.12420

Mandarelli, G. et al. (2018). Treatment decision-making capacity in non-consensual psychiatric treatment: a multicentre study. Epidemiology and Psychiatric Sciences, 27, 492-499. https://doi.org/10.1017/S2045796017000063

Mandarelli, G. et al. (2019). Decisional capacity to consent to treatment and anaesthesia in patients over the age of 60 undergoing major orthopaedic surgery. Medicine, Science 
and the Law, 59, 247-254. https://doi.org/10.1177/ 0025802419865854

Mandarelli, G., Parmigiani, G., Tarsitani, L., Frati, P., Biondi, M. and Ferracuti, S. (2012). The relationship between executive functions and capacity to consent to treatment in acute psychiatric hospitalization. Fournal of Empirical Research on Human Research Ethics, 7, 63-70. https://doi.org/10.1525/je

Marson, D. C., Chatterjee, A., Ingram, K. K. and Harrell, L. E. (1996). Toward a neurologic model of competency: cognitive predictors of capacity to consent in Alzheimer's disease using three different legal standards. Neurology, 46, 666-672. https://doi.org/10.1212/wnl.46.3.666

Marson, D. C., Ingram, K. K., Cody, H. A. and Harrel, L. E. (1995). Assessing the competency of patients with Alzheimer's disease under different legal standards: a prototype instrument. Archives of Neurology, 52, 949-954. https://doi.org/10.1001/archneur.1995.00540340029010

Marson, D. C., McInturff, B., Hawkins, L., Bartolucci, A. and Harrell, L. E. (1997). Consistency of physician judgments of capacity to consent in mild Alzheimer's disease. Fournal of the American Geriatric Society, 45, 453457. https://doi.org/10.1111/j.1532-5415.1997.tb05170.x

Martin, R. C. et al. (2008). Medical decision-making capacity in cognitively impaired Parkinson's disease patients without dementia. Movement Disorders, 23, 1867-1874. https://doi.org/10.1002/mds. 22170

Mittal, D. et al. (2007). Comparison of two enhanced consent procedures for patients with Mild Alzheimer Disease or Mild Cognitive Impairment. The American fournal of Geriatric Psychiatry, 15, 163-167. https://doi.org/ 10.1097/JGP.0b013e31802dd379

Moye, J. and Karel, M. J. (1999). Evaluating decisional capacities in older adults: results of two clinical studies. Advances in Medical Psychotherapy, 10, 71-84.

Moye, J., Karel, M. J., Gurrera, R. J. and Azar, A. R. (2006). Neuropsychological predictors of decision-making capacity over 9 months in mild-to-moderate dementia. fournal of General Internal Medicine, 21, 78-83. https://doi .org/10.1111/j.1525-1497.2005.00288.x

Okonkwo, O. et al. (2007). Medical decision-making capacity in patients with mild cognitive impairment. Neurology, 69, 1528-1535. https://doi.org/10.1212/01.wnl $.0000277639 .90611 . \mathrm{d} 9$

Okonkwo, O. C. et al. (2008a). Cognitive models of medical decision-making capacity in patients with mild cognitive impairment. Fournal of the International Neuropsychological Society, 14, 297-308. https://doi.org/10.1017/ S1355617708080338

Okonkwo, O. C. et al. (2008b). Medical decision-making capacity in mild cognitive impairment. A 3-year longitudinal study. Neurology, 71, 1474-1480. https://doi.org/10.1212/ 01.wnl.0000334301.32358.48

Oshima, E. et al. (2020). Competency of aMCI patients to consent to cholinesterase treatment. International Psychogeriatrics, 32, 211-216. https://doi.org/10.1017/ S1041610219000516

Palmer, B. W. et al. (2005). Assessment of capacity to consent to research among older persons with schizophrenia, Alzheimer disease, or diabetes mellitus. Comparison of a 3item questionnaire with a comprehensive standardized capacity instrument. Archives of General Psychiatry, 62, 726733. https://doi.org/10.1001/archpsyc.62.7.726

Palmer, B. W. et al. (2018). Multimedia aided consent for Alzheimer's disease research. Clinical Gerontologist, 41, 2032. https://doi.org/10.1080/07317115.2017.1373177

Palmer, B. W., Dunn, L. B., Appelbaum, P. S. and Jeste, D. V. (2004). Correlates of treatment-related decision-making capacity among middle-aged and older patients with schizophrenia. Archives of General Psychiatry, 61, 230-236. https://doi.org/10.1001/archpsyc.61.3.230

Palmer, B. W. and Harmell, A. L. (2016). Assessment of healthcare decision-making capacity. Archives of Clinical Neuropsychology, 31, 530-540. https://doi.org/10.1093/ arclin/acw051

Palmer, B. W. and Savla, G. N. (2007). The association of specific neuropsychological deficits with capacity to consent to research or treatment. Fournal of the International Neuropsychological Society, 13, 1047-1059. https://doi.org/10 $.1017 /$ S1355617707071299

Parmigiani, G., Mandarelli, G., Dacquino, C., Pompili, P., Lelli Chiesa, G. and Ferracuti, S. (2016). Decisional capacity to consent to clinical research involving placebo in psychiatric patients. Fournal of Forensic Sciences, 61, 388-393. https://doi.org/10.1111/1556-4029.13000

Petersen, R. C. et al. (2005). Vitamin E and donepezil for the treatment of mild cognitive impairment. The New England Fournal of Medicine, 352(23), 2379-2388. https:// doi.org/10.1056/NEJMoa050151

Petersen, R. C. and Morris, J. C. (2005). Mild cognitive impairment as a clinical entity and treatment target. Archives of Neurology, 62, 1160-1163. https://doi.org/10.1001/ archneur.62.7.1160

Raymont, V.et al. (2004). Prevalence of mental incapacity in medical inpatients and associated risk factors: crosssectional study. The Lancet, 364, 1421-1427. https://doi .org/10.1016/s0140-6736(04)17224-3

Rubright, J., Sankar, P., Casarett, D. J., Gur, R., Xie, S. X. and Karlawish, J. (2010). A memory and organizational aid improves Alzheimer disease research consent capacity: results of a randomized, controlled trial. The American Fournal of Geriatric Psychiatry, 18, 1124-1132. https://doi .org/10.1097/JGP.0b013e3181dd1c3b

Simpson, C. (2010). Decision-Making capacity and informed consent to participate in research by cognitively impaired individuals. Applied Nursing Research, 23, 221226. https://doi.org/10.1016/j.apnr.2008.09.002

Stroup, S. et al. (2005). Decision-Making capacity for research participation among individuals in the CATIE schizophrenia trial. Schizophrenia Research, 80, 1-8. https:// doi.org/10.1016/j.schres.2005.08.007

Szmukler, G., Bach, M. (2015).Mental health disabilities and human rights protections. Global Mental Health, 2, e20. https://doi.org/10.1017/gmh.2015.18.eCollection2015.

Szmukler, G., Daw, R., Callard, F. (2014). Mental health law and the UN Convention on the rights of persons with disabilities. International Fournal of Law and Psychiatry, 37, 245-252. https://doi.org/10.1016/j.ijlp.2013.11.024

UN General Assembly (2006). Convention on the rights of persons with disabilities, 13 December, A/RES/61/106. Available at: https://www.un.org/development/desa/ disabilities/convention-on-the-rights-of-persons-with- 
disabilities/convention-on-the-rights-ofpersons-withdisabilities-2.html; last accessed 30 September 2020

van Duinkerken, E., Farme, J., Landeira-Fernandez, J., Dourado, M., Laks, J. and Mograbi, D. C. (2018).
Medical and research consent decision-making capacity in patients with Alzheimer's disease: a systematic review.

Fournal of Alzheimer's Disease, 65, 917-930. https://doi.org/ 10.3233/JAD-180311 